\title{
Intestinal protozoan infections among HIV positive persons with and without Antiretroviral Treatment (ART) in selected ART centers in Adama, Afar and Dire-Dawa, Ethiopia
}

\author{
Haileeyesus Adamu ${ }^{1}$, Beyene Petros ${ }^{2}$
}

\begin{abstract}
Background: In developing countries, gastroenteritis caused by intestinal parasites may be complicated and is a major cause of morbidity, in general, and kills millions of AIDS patients annually. Thus, the consequences of parasitic diseases are among the major health problems in tropical developing countries.

Methods: A total of 200 HIV positive patients on and without-ART aged from 18 to 65 years, of both sexes participated in the study. Each study participant was provided with a faecal collection vial containing $10 \%$ formalin for microscopic examination of ova, larvae, and cysts. For detection of Cryptosporidium spp, lsospora belli and Cyclospora spp, the modified Zeihl-Neelsen staining method was used.

Results: Most (60\%) of the study participants were on antiretroviral therapy (ART). Out of those, only two (1.5\%) were diagnosed with an opportunistic parasite, and $96(48 \%)$ of the non-ART study participants were infected with at least one other intestinal parasite species. The prevalence was 16\% for Giardia lamblia, $13 \%$ for Entamoeba histolytical E. dispar, $8 \%$ for Cryptosporidium spp, 5\% for Isospora belli, 1.5\% for Blastocystis hominis, 2.5\% for Ascaris lumbricoides and 2\% for Hymnolepis nana. Diarrhoea was significantly associated with cryptosporidiosis, giardiasis, and isosporiasis. Significant association was observed between lower $\mathrm{CD}^{+} \mathrm{T}$ cell count $(<200 \mathrm{cells} / \mu \mathrm{L})$ and the prevalence of Cryptosporidium spp, Isospora belli, and Blastocystis hominis. The three parasites were significantly prevalent in HIV sero-positive patients not on -ART.

Conclusion: The finding showed that patients under ART had lower prevalence of diarrheogenic protozoan parasites suggesting that ART through improvement of the immune status of patients may have contributed to controlling parasites in HIV/AIDS patients. [Ethiop. J. Health Dev. 2009;23(2):133-140]
\end{abstract}

\section{Introduction}

Human immunodeficiency virus (HIV) infection, a worldwide phenomenon, is a serious public health problem (1). HIV infection has globally claimed over 20 million lives, and currently over 40 million people carry the infection (2). Even though AIDS remains a global pandemic, Ethiopia is one of the highly affected SubSaharan countries.

It is estimated that as much as $60 \%$ of the World's population is infected with intestinal parasites, which may play a significant role in morbidity due to intestinal infections (3). Intestinal parasitic infections are among the most common infections world-wide. It is estimated that some 3.5 billion people are affected, and 450 million are ill as a result of these infections (4). The rate of infection is remarkably high in Sub-Saharan Africa, where the majority of HIV and AIDS cases are concentrated (5). The incidence of intestinal parasitic infections is $50 \%$ in developed countries, whereas it reaches up to $95 \%$ in developing countries. These infections are caused both by protozoa and helminths and the main clinical manifestation of the disease caused by them is diarrhoea (6).

In developing countries, acute gastroenteritis caused by intestinal parasites is complicated and it is a major cause of illness and kills millions of AIDS patients annually (7). Reports indicate that diarrhoea occurs in $30-60 \%$ of AIDS patients in developed countries, whereas it reaches up to $90 \%$ in developing countries (8). The progressive decline of mucosal immunologic defence mechanisms predisposes patients to precocious, intermediate, or late gastrointestinal manifestations such as diarrhoea (9). In the late stages of AIDS, the protective effects of nonspecific defence mechanisms, production of IgA antibodies and local cellular immune responses are diminished, thus increasing susceptibility to various intestinal opportunistic agents, such as Cryptosporidium parvum, Isospora belli, and Microsporidiium species (10).

After the emergence of AIDS, opportunistic parasites, known until then solely in veterinary medicine, were no longer considered commensal organisms, and they currently are recognized as common opportunist pathogens affecting HIV infected patients, constituting a major secondary aggravating factor of the disease. These enteric infections frequently cause severe diarrhoea, which often is responsible for the grievousness of the disease, and may sometimes lead to death.

${ }^{T}$ Department of Biology (PhD Student), Addis Ababa University, P. O. Box 42524, Addis Ababa, Ethiopia. E-mail: haile27@gmail.com; ${ }^{2}$ Department of Biology, Addis Ababa University, P. O. Box 1176, Addis Ababa, Ethiopia. Email: abule2002@yahoo.com 
In general, diarrhoeal diseases are significant causes of morbidity and mortality in all age groups, but immunocompromised and pediatric patients experience more frequent and severe illnesses (11). Moreover, nowadays diarrhoeal illnesses are becoming one of the most common clinically observable gastrointestinal manifestations in AIDS patients, occurring at late stages of HIV infection; usually due to opportunistic infections (12).

Intestinal parasites are highly prevalent in Ethiopia due to shortage of clean water, lack of sewage system and other unhygienic factors that increase the probability of infection. The purpose of this study was to test the hypothesis that ART will reduce the prevalence of diarrheogenic protozoan parasites in HIV/AIDS patients.

\section{Methods}

The study area: The study was carried out in selected Health Centers with ART service at Adama $100 \mathrm{~km}$ from the capital Addis Ababa, Afar ("Awash Sebat Kilo"), $225 \mathrm{~km}$ from Addis Ababa and Dire-Dawa which is 525 $\mathrm{km}$ from Addis Ababa, Ethiopia from December 2007 to January 2008. The study sites were selected considering the location, cost and time constraints.

The study population: The study participants were people living with HIV (PLHIV) of both sexes 18 to 65 years of age on and not on ART selected randomly. Socio-demographic and clinical information including diarrhoea and medication histories were obtained from the study participants by interview and their $\mathrm{CD}^{+}{ }^{+} \mathrm{T}$-cell counts were obtained from their medical records at the Health Centers. CD4 ${ }^{+}$T-cell counts were considered only when it was done at the time of or very close to stool sample collection.

Stool collection and processing: A single fresh stool sample was collected from consenting study participants $(n=200)$. The questionnaires concerning the prevalence were filled by the principal investigator who interviewed the study participants during sample collection. A portion of the stool was preserved in $10 \%$ formalin in a proportion of $10 \mathrm{~g}$ of stool in $3 \mathrm{ml}$ of formalin (13).

Direct Microscopy (Wet mount): A direct wet mount of stool in normal saline $(0.85 \% \mathrm{NaCl}$ solution $)$ was prepared at Adama, Afar ("Awash Sebat Kilo") and DireDawa ART Centers; and examined for the presence of motile intestinal parasites and trophozoites under light microscope (400X magnification). Lugol's iodine staining was used to detect cysts of intestinal parasites.

Formalin-Ether concentration: Using an applicator stick, about $5 \mathrm{~g}$ of preserved stool sample was placed in a clean $15 \mathrm{ml}$ conical centrifuge tube containing $7 \mathrm{ml}$ of $10 \%$ formalin. The sample was dissolved and mixed thoroughly with applicator stick. The resulting suspension was filtered through a sieve (cotton gauze) into a beaker and the filtrate poured back into the same tube. The debris trapped on the sieve was discarded. After adding $3 \mathrm{ml}$ of $99.5 \%$ diethyl ether to the mixture and hand shaking, the content was centrifuged at 2000 rpm for 3 minutes. The supernatant was poured away and the tube was placed in its rack. The sediments were stained with Iodine and put on slide and covered with cover slip. The entire area under the cover slip was examined using 400X objective magnification (14). Microscopic examinations were done independently by experienced clinical laboratory technicians; the determination and verification was finally made by the investigator.

Modified Zeihl-Neelsen Method: Modified ZeihlNeelsen staining; based on direct and concentration methods, for detection of oocysts of opportunistic coccidial intestinal parasite-Cryptosporidium spp, Isospora belli, Cyclospora cayetanensis was done. Fresh faecal samples were collected and thin smears were prepared, air-dried, fixed with methanol for 5 minutes in the field and stained by Zeihl-Neelsen technique at the Biomedical Sciences Laboratory of the Department Biology, Addis Ababa University. The same procedures were used for smears prepared after concentration. Smears were prepared from the concentrated stool samples and were stained as described by Adegbola et al. (15) with some modifications. In this technique, the slides were stained with carbol-fuchsine for 30 minutes and then were washed with tap water. The slides were decolorized in $1 \% \mathrm{HCl}$ acid-alcohol for 1 minute and were counter stained with $1 \%$ ethylene blue for another 1 minute. Finally, the stained smears were microscopically examined using 1000x magnification (16).

Data analysis: Statistical analysis was done by using SPSS version 13.0. Data were summarized using frequency tables and bar charts. Categorical risk factors for diarrhoea analyzed; and the strength of association measured by using the chi-square and its associated pvalue. Values were considered to be statistically significant when the $\mathrm{p}$-value obtained was less or equal to 0.05 .

Ethical Consideration: This study was conducted with the approval of the Ethical Review Committee on Health Research, Faculty of Science, Department of Biology, Addis Ababa University. Informed written consent was obtained from each study participant. Participants were also informed that they are free to withdraw consent any time and their medical records and specimens were examined by qualified persons. More over, all personal information of the participants was treated strictly confidential. Study participants positive for intestinal parasites were treated for free using standard drugs. The drugs were administered by clinicians working at the study sites. 


\section{Results}

A total of $200 \mathrm{HIV}$ sero-positive individuals participated in this study. Among those, 110 (55\%) were males and $90(45 \%)$ were females. The mean age of the study participants was 41.5 years (range: 18 to 65 ). The majority, $143(71.5 \%)$, were from the rural vicinities of the towns. They had direct and indirect contact with domestic animals. Of the total study participants, 62 $(31 \%)$ were from Adama and its surroundings, while 70 (35\%) were from Afar ("Awash Sebat Kilo") and 68 $(34 \%)$ were residents of Dire-Dawa and its surroundings (Table 1).

Table 1: Age, Sex and Area distribution of study participants $(n=200)$ in Adama, Afar and Dire-Dawa, Ethiopia (2008).

\begin{tabular}{|c|c|c|c|c|c|c|c|}
\hline \multirow{3}{*}{$\begin{array}{l}\text { Age } \\
\text { Group }\end{array}$} & \multicolumn{6}{|c|}{ Study Sites } & \multirow{3}{*}{$\begin{array}{l}\text { Total } \\
\text { n (\%) }\end{array}$} \\
\hline & \multicolumn{2}{|c|}{ Adama } & \multicolumn{2}{|c|}{ Afar } & \multicolumn{2}{|c|}{ Dire-Dawa } & \\
\hline & $\begin{array}{l}\text { Male } \\
\mathrm{n}(\%)\end{array}$ & $\begin{array}{c}\text { Female } \\
\mathrm{n}(\%)\end{array}$ & $\begin{array}{l}\text { Male } \\
\mathrm{n}(\%)\end{array}$ & $\begin{array}{c}\text { Female } \\
\mathrm{n}(\%)\end{array}$ & $\begin{array}{l}\text { Male } \\
\mathrm{n}(\%)\end{array}$ & $\begin{array}{c}\text { Female } \\
\mathrm{n}(\%)\end{array}$ & \\
\hline $18-35$ years & $18(52.9)$ & $8(28.6)$ & $17(46)$ & $15(45.6)$ & $17(43.6)$ & $7(24)$ & $82(41)$ \\
\hline $36-53$ years & $10(29.4)$ & $12(42.8)$ & 6 (16.2) & 13 (39.4) & $7(18)$ & $11(38)$ & 59 (29.5) \\
\hline $54-65$ years & $6(17.7)$ & $8(28.6)$ & $14(37.8)$ & $5(15.0)$ & $15(38.4)$ & $11(38)$ & 59 (29.5) \\
\hline Total & $34(100)$ & $28(100)$ & $37(100)$ & $33(100)$ & $39(100)$ & $29(100)$ & $200(100)$ \\
\hline
\end{tabular}

Based on parasitological examination of the stool specimens, 7 species of intestinal parasites were detected in $96(48 \%)$ in the HIV sero-positive patients. The detected parasites included: Giardia lamblia 32 (16\%), Entamoeba histolytica/E. dispar 26 (13\%), Ascaris lumbricoides 5 (2.5\%), Hymenolepis nana 4 (2\%),
Cryptosporidium spp 16 (8\%), Isospora belli $10(5 \%)$ and Blastocystis hominis $3(1.5 \%)$. G. lamblia 15 (46.9\%) and E. histolytica/ dispar 14 (54\%) were most prevalent in the Afar region (Table 2). G. lamblia was the most common intestinal parasite associated with poor living condition (Table 5) among the study participants.

Table 2: The overall prevalence of intestinal parasites among HIV positive individuals ( $n=96)$ in selected ART centers in Adama, Afar and Dire-Dawa, Ethiopia (2008).

\begin{tabular}{|c|c|c|c|c|}
\hline \multirow{2}{*}{ Parasites } & \multicolumn{3}{|c|}{ Study Sites } & \multirow[b]{2}{*}{$\begin{array}{l}\text { Total } \\
\text { n (\%) }\end{array}$} \\
\hline & $\begin{array}{c}\text { Adama } \\
\mathrm{n}(\%)\end{array}$ & $\begin{array}{l}\text { Afar } \\
\text { n (\%) }\end{array}$ & $\begin{array}{c}\text { Dire-Dawa } \\
\mathrm{n}(\%)\end{array}$ & \\
\hline G. lamblia & $9(28.1)$ & $15(46.9)$ & $8(25)$ & $32(16)$ \\
\hline E. histolytica/E. dispar & $7(27)$ & $14(54)$ & $5(19)$ & $26(13)$ \\
\hline Cryptosporidium spp & $10(62.5)$ & $2(12.5)$ & $4(25)$ & $16(8)$ \\
\hline I. belli & $6(60)$ & $1(10)$ & $3(30)$ & $10(5)$ \\
\hline A. lumbricoides & $2(40)$ & $3(60)$ & 0 & $5(2.5)$ \\
\hline H. nana & 0 & $4(100)$ & 0 & $4(2)$ \\
\hline B. hominis & 0 & $3(100)$ & 0 & $3(1.5)$ \\
\hline Total & $34(35.4)$ & $42(43.8)$ & $20(66.4)$ & $96(48)$ \\
\hline
\end{tabular}

Among the 200 study participants, 75 (37.5\%) had diarrhoeic stools. Among the 104 parasite-negative stool samples, only $12(19.3 \%)$ were diarrhoeic. Conversely, $60(80 \%)$ patients positive for gastrointestinal symptom (diarrhoea) were significantly $(\mathrm{p}<0.05)$ associated with G. lamblia, Cryptosporidium spp and I. belli infections, whereas $A$. lumbricoides was more frequently detected in non-diarrhoeal patients (Table 3).

Most of the study participants, $120(60 \%)$ were on antiretroviral therapy (ART). Out of those only two $(12.5 \%)$ were diagnosed with an opportunistic parasite (Table 3). $83(41.5 \%)$ study participants were on antibiotic Cotrimoxazole (bacterium), while only 37 $(18.5 \%)$ were on both antibiotic and ART. Among those who took ART and the antibiotic, none were positive for opportunistic parasites. Furthermore, infections with the opportunistic parasites Cryptosporidium spp and I. belli were significantly higher in HIV positives who were not taking ART $(\mathrm{p}<0.05)$ (Table 3$)$. 
Table 3: Association between the presence of parasites among HIV positive diarrhoeic $(n=84)$ and nondiarrhoeic $(n=12)$ individuals on ART $(n=46)$ and without ART $(n=50)$ in selected ART centers from Adama, Afar and Dire-Dawa, Ethiopia (2008).

\begin{tabular}{|c|c|c|c|c|c|c|}
\hline \multirow[b]{2}{*}{ Parasites } & \multicolumn{3}{|c|}{ Faecal aspect } & \multicolumn{3}{|c|}{ ART status } \\
\hline & $\begin{array}{l}D^{*} \\
n(\%)\end{array}$ & $\begin{array}{l}\text { ND }^{* *} \\
\mathrm{n}(\%)\end{array}$ & P-value & ART & Non-ART & P-value \\
\hline G. lamblia & $31(96.9)$ & $1(3.1)$ & $<0.01$ & $21(63.6)$ & $11(36.4)$ & $>0.05$ \\
\hline E. histolytica/E. Dispar & $26(100)$ & 0 & & $14(54)$ & $12(46)$ & \\
\hline Cryptosporidium spp & $14(87.5)$ & $2(12.5)$ & & $2(12.5)$ & $14(87.5)$ & $<0.05$ \\
\hline I. belli & $9(90)$ & $1(10)$ & & 0 & $10(100)$ & \\
\hline A. lumbricoides & 0 & $5(100)$ & nd & $5(100)$ & 0 & nd \\
\hline H. nana & $1(33.3)$ & $3(77.7)$ & nd & $4(100)$ & 0 & nd \\
\hline B. hominis & $3(100)$ & 0 & nd & 0 & $3(100)$ & nd \\
\hline Total & $84(87.4)$ & $12(12.5)$ & & $46(48)$ & $50(52)$ & \\
\hline
\end{tabular}

$\mathrm{D}^{*}=$ Diarrhoeic, $\quad \mathrm{DN}^{* *}=$ Non-Diarrhoeic,

Non-ART=without-Antiretroviral treatment

ART=With antiretroviral treatment

nd=not determined

Although almost one third of the patients (33\%) reported some direct physical contact with cattle and other domestic animals, including dogs, cats and chicken, there was no association between physical contact with domestic animals and infection with Cryptosporidium spp (data not shown) $(\mathrm{p}>0.05)$.

From the $96 \mathrm{HIV}$ and intestinal parasite co-infected study participants, $31.2 \%$ had $\mathrm{CD}^{+} \mathrm{T}$ cell count $>500 / \mu \mathrm{L}$, $30.2 \%$ had $\mathrm{CD}^{+} \mathrm{T}$ cell count between $200-499 / \mu \mathrm{L}$, and $38.6 \%$ had $\mathrm{CD}^{+}{ }^{\mathrm{T}} \mathrm{T}$ cell count $<200 / \mu \mathrm{L}$. Cryptosporidium spp and I. belli were associated with the lower $\mathrm{CD}^{+} \mathrm{T}$ cell counts $(<200 / \mu \mathrm{L})-62.5 \%$ Cryptosporidium spp and $60 \%$ I. belli ( $\mathrm{p}$ value $<0.05$ ). All the 3 patients parasitized by $B$. hominis had lower $\mathrm{CD}^{+} \mathrm{T}$ cell count $(<200 / \mu \mathrm{L})$ (Table 4).

Table 4: Prevalence of intestinal parasite infection among HIV positive individuals and their $\mathrm{CD4}^{+} \mathrm{T}$ cell $(\mathrm{n}=96)$ in selected ART centers of Adama, Afar and Dire-Dawa, Ethiopia (2008).

\begin{tabular}{|c|c|c|c|}
\hline \multirow{2}{*}{ Parasites } & \multicolumn{3}{|c|}{ CDR+ T-Cell count } \\
\hline & $\begin{array}{l}>500 / \mu \mathrm{L} \\
\mathrm{n}(\%)\end{array}$ & $\begin{array}{l}200-499 / \mu \mathrm{L} \\
\text { n (\%) }\end{array}$ & $\begin{array}{l}<200 / \mu \mathrm{L} \\
\mathrm{n}(\%)\end{array}$ \\
\hline G. lamblia & $15(46.9)$ & $8(25)$ & $9(28.1)$ \\
\hline E. histolytica/E. dispar & $5(19)$ & $14(54)$ & $7(27)$ \\
\hline Cryptosporidium spp & $2(12.5)$ & $4(25)$ & $10(62.5)^{*}$ \\
\hline I. belli & $1(10)$ & $3(30)$ & $6(60)^{*}$ \\
\hline A. lumbricoides & $3(60)$ & 0 & $2(40)$ \\
\hline H. nana & $4(100)$ & 0 & 0 \\
\hline B. hominis & 0 & 0 & $3(100)$ \\
\hline Total & $30(31.2)$ & $29(30.2)$ & 37 (38.6) \\
\hline
\end{tabular}

All types of parasite species were detected in study participants with lower educational levels. Cryptosporidium spp and Isospora belli were almost similarly detected in all educational levels (grade 6 to 12) with infections declining among those with higher education $(\mathrm{P}<0.05)$ (Fig. 1).

A correlation between poor living conditions and presence of parasites was evident. That is, from the total of 96 parasite-positive individuals, 84 (87.5\%) were living in "poor" conditions (high degree of crowding, low quality of water supply, improper disposal of excreta and unfinished or semi-finished type of floor), whereas 12 $(12.5 \%)$ were living in "good" conditions (low degree of crowding, tape water supply, proper disposal of execreta and cemented and finished type of floor) (Tellez et al., 1997) (Table 5). 


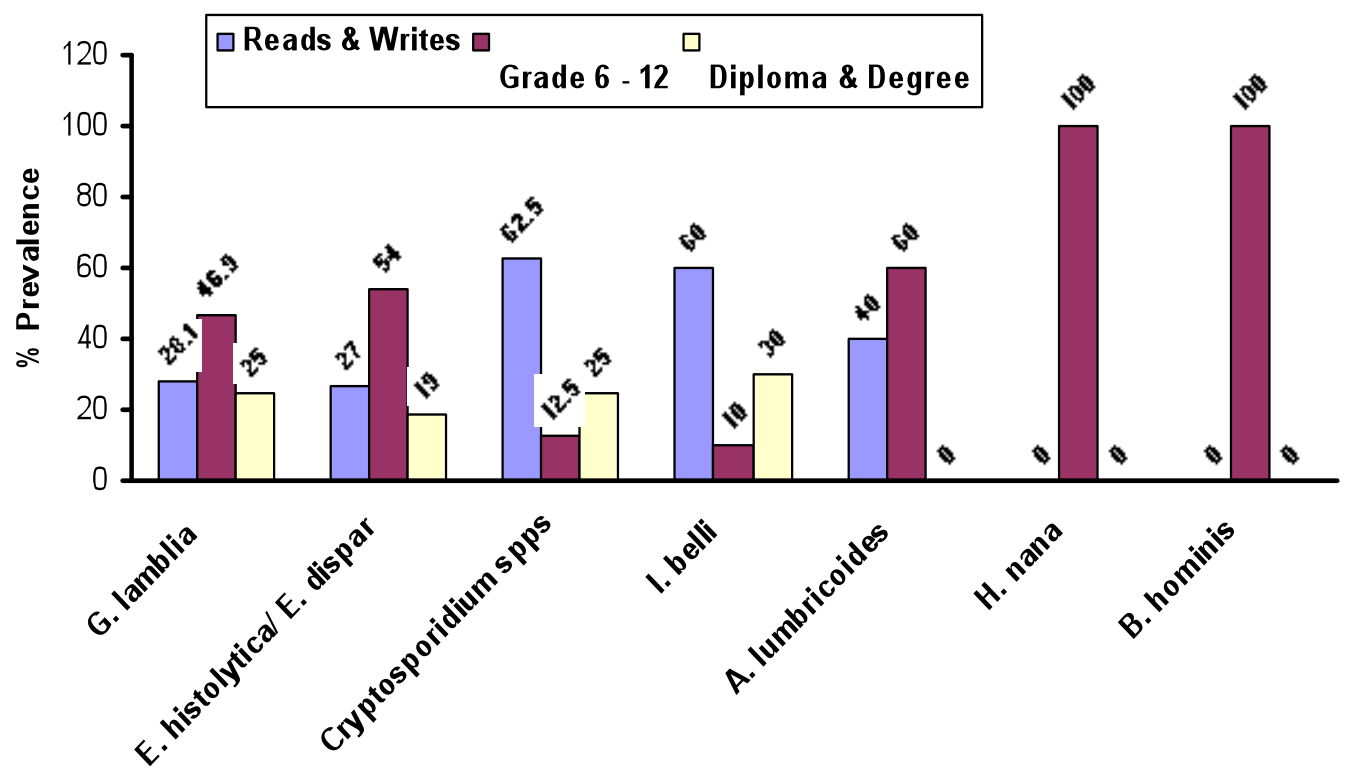

Parasites

Figure 1: Prevalence of opportunistic and common intestinal parasite infection and education status of HIV positive individuals ( $n=96$ ) in selected ART centers of Adama, Afar and Dire-Dawa, Ethiopia (2008).

Table 5: Prevalence of common intestinal parasite infections and living conditions of HIV positive individuals $(n=96)$ in selected ART centers of Adama, Afar and Dire-Dawa, Ethiopia (2008).

\begin{tabular}{|c|c|c|c|}
\hline \multirow{2}{*}{ Parasites } & \multicolumn{3}{|c|}{ Living condition* } \\
\hline & $\begin{array}{c}\text { Poor } \\
\text { n (\%) }\end{array}$ & $\begin{array}{l}\text { Good } \\
\mathrm{n}(\%)\end{array}$ & \\
\hline G. lamblia & $31(96.9)$ & $1(3.1)$ & $\mathrm{P}<0.001$ \\
\hline E. histolytica/E. dispar & $21(80.8)$ & $5(19.2)$ & $\mathrm{P}<0.01$ \\
\hline Cryptosporidium spp & $12(75)$ & $4(25)$ & \\
\hline I. belli & $8(80)$ & $2(20)$ & \\
\hline A. lumbricoides & $5(100)$ & 0 & nd \\
\hline H. nana & $4(100)$ & 0 & \\
\hline B. hominis & $3(100)$ & 0 & \\
\hline Total & $84(87.5)$ & $12(12.5)$ & \\
\hline
\end{tabular}

*Living conditions were considered as good versus poor considering the degree of crowding, quality of water supply, disposal of excretion and type of floor (Tellez et al, 1997).

nd=not determined

\section{Discussion}

This study reports the prevalence of opportunistic and common intestinal parasitic infections among HIV positive persons on ART and without ART in selected ART centers - Adama, Afar ("Awash Sebat Kilo") and Dire-Dawa, Ethiopia. Among the opportunistic parasites, I. belli, Cryptosporidium spp and B. hominis were detected in our study. These parasites were previously reported from AIDS patients and children less than five years of age with and without diarrhoea in Addis Ababa and elsewhere $(12,17)$.

As diarrhoea is an important gastrointestinal syndrome in HIV infected patients, a comparison was conducted between the associated intestinal parasites in diarrhoeic and non-diarrhoeic patients. Among the faecal samples for parasite identification, the diarrhoeic states were closely associated with the presence of parasites in the stool samples. This association is in agreement with other studies showing that only $20 \%$ of the diarrheic patients with AIDS presented an obscure etiology, whereas in more than $50 \%$ (of patients) parasites were diagnosed (18).

The significant association between parasite positivity and diarrhoea was more evident for $G$. lamblia, Cryptosporidium spp, I. belli, E. histolytica/ E. dispar and $B$. hominis infections. Previous studies in Ethiopia 
have also shown that among patients infected with HIV, infection rate of $8 \%$ and $5 \%$ for $I$. belli and Cryptosporidium spp, were reported, respectively (16, 17).

Although the role of $I$. belli as an opportunistic infection in people with AIDS is prominent (19), there are only few published reports so far in Ethiopia $(20,21)$. The actual rate of this infection in immuno-competent individuals is likely to be underestimated because of healthy appearance of asymptomatic carriers that shed oocysts and treatment with cotrimoxazole and other antibiotics for other infections may confer some protection against this protozoan in AIDS patients (10, 19).

Although the prevalence of cryptosporidiosis in humans is relatively high in Ethiopia, there is no confirmation on whether the species responsible is only $C$. parvum or $C$. hominis, both of them or other species of Cryptosporidium. This will involve molecular typing of the isolates following analysis with Polymerase Chain Reaction (PCR). Such knowledge will also indicate the extent of zoonotic spread of the disease.

This study showed that opportunistic parasitic infections are common among HIV positive patients and that there exists a relationship between the type of parasite and $\mathrm{CD}^{+}$T-cell count. The prevalence of opportunistic protozoan parasites tended to be higher in HIV positive patients with lower $\mathrm{CD}^{+} \mathrm{T}$-cell count. This finding is similar to what was reported in Cameroon (22). The prevalence of intestinal parasites reported in this study $(48 \%)$ is comparable to a study from Jimma University Teaching Hospital in Ethiopia (21).

The prevalence rates of Cryptosporidium spp, Isospora belli and Blastocystis hominis were higher in comparison to the rate reported by Awole and his associates from South Western Ethiopia (20). It is known that geographical location and levels of general hygiene play a significant role in the distribution of parasites. Although Blastocystis hominis is believed to be nonpathogenic by many, recent studies have implicated its involvement in diarrhoea, especially in immunocompromised HIV/AIDS patients $(23,24)$.

The distribution of intestinal parasites appeared to be higher within the age group $18-35$ years and in females, which is similar to the report of Fleming (23). The females milk cattle and clean animal dung from resting places and hence the observed higher prevalence rates could probably reflect direct and indirect exposure frequencies of the individuals.

There exists a difference in the prevalence of parasites between patients on ART and not on ART. The overall prevalence of intestinal parasites was significantly higher in HIV sero-positive patients who did not start ART and hence had lower $\mathrm{CD} 4^{+}$T-cell count. This is associated with immuno-suppression, which may enhance parasite establishment and may thus increase parasite load. Thus, these parasites can be easily detected and identified in stool samples of HIV positive patients who did not start ART.

Since Cyclospora spp infections are more associated with wet season $(25,26)$ and the study was conducted during the dry season (December and January), its absence is to be expected. Furthermore, the failure to detect Cyclospora spp may be related to the widespread use of cotrimoxazole, by people living with HIV/AIDS as a prophylactic measure against opportunistic infections. The use of this antibiotic against bacterial infections may therefore have additional beneficial effects in curbing some parasitic infections.

Cryptosporidium spp and $I$. belli infections were significantly higher in HIV/AIDS patients who were not enrolled on ART compared to those enrolled on ART and with $\mathrm{CD} 4{ }^{+} \mathrm{T}$-cell count $>200$ cells $/ \mu \mathrm{L}$. This indicated that there is low opportunity for these parasites to get established as the patients $\mathrm{CD} 4^{+}$count increased.

Cryptosporidium spp are common opportunistic parasites that cause chronic diarrhoea and wasting in HIV/AIDS patients with $\mathrm{CD}^{+}$T-cell counts $<100$ cells $/ \mu \mathrm{L}$ and antimicrobial agents have limited efficacy in preventing or eradicating infections with it. Although studies assessing reduction in the incidence of cryptosporidiosis are lacking, diarrhoea due to cryptosporidia are known to resolve spontaneously with immune restoration among HIV/AIDS patients on ART $(27,28)$.

Mekonnen (29) reported higher prevalence of intestinal helminth infections among HIV infected individuals at the time of initiation of ART in patients whose $\mathrm{CD}^{+} \mathrm{T}$ cell count is less than 200 cells/ $\mu \mathrm{L}$ than among non-ART HIV-positives whose $\mathrm{CD}^{+} \mathrm{T}$ cell count is more than 200 cells $/ \mu \mathrm{L}$. The helminth prevalence was not high in our study.

All parasite species were detected in lower educational levels. The finding that parasite infections declined with increased educational level of the study participants indicated the overall improvement of hygienic conditions and sanitation with education. Another study had shown such a relation between increase in educational level and lower incidence of intestinal parasite infection (30).

It is possible that some parasites were not detected in this study because not all techniques such as the water-ether sedimentation method for Microsporidia or adhesive tape or anal swab for Enterobius vermicularis were not used. Therefore, the prevalence of intestinal parasites among the study participants may have been underestimated. From this study we can conclude that ART will reduce diarrhoea prevalence caused by protozoan infections in 
AIDS patients. The data support the value of standard faecal examinations in HIV positive individuals, since these examinations can be easily performed with low costs allowing initiation of provision of the therapeutic approaches.

Based on this study, we would recommend the following: public health measures should continue to emphasize the importance of environmental and personal hygiene as well as provide and monitor the quality of drinking water; there must be more education and training to health practitioners and lab technicians about opportunistic emerging diarrhoea-causing parasites; there is a need to elucidate the potential sources of opportunistic parasites for people living with HIV/AIDS; future efforts should determine the prevalence of these parasites in pets and domestic animals in Ethiopia; and through the use of genotyping techniques, compare isolates of Cryptosporidium spp from HIV infected persons to determine potential animal reservoirs and drinking water. A well designed study is recommended to determine the true prevalence of these parasitic infections in PLWHA in Ethiopia. More effort is needed to provide easy access to HIV care services, and to expand the availability of ART. In addition, constant reinforcement of patient adherence to antiretroviral and antimicrobial therapies and prophylaxis, for HIV/AIDS patients will be most appropriate.

\section{Acknowledgements}

We would like to express our gratitude to Dr Gurja Belay, Head Department of Biology for his usual support and facilitation of the work on time. Our special thanks to ART Centers in Adama, Afar and Dire-Dawa, especially Desalegn Yazew from Save the Children USA, for his unreserved support. We would also like to give our special thanks to Save the Children USA; which enabled us to use its vehicle for field work in all the study sites. All the study participants deserve many thanks for their willingness to participate in this research. Finally, we would like to thank the School of Graduate Studies Addis Ababa University for the financial support.

\section{References}

1. Wiwanitkit, V. Intestinal parasitic infections in Thai $\mathrm{HIV}$-infected patients with different immunity status. BMC Gastroenterol 2001;1:1-3.

2. UNAIDS Report on the Global AIDS Epidemic. Geneva, UNAIDS, 2007.

3. WHO (1987). Prevention and Control of Intestinal parasitic Infections. WHO Technical Report. 1987;749: 1-86.

4. WHO (1998). Control of Tropical Diseases. WHO, Geneva.

5. UNAIDS/ WHO HIV Epidemic Update. Geneva. UNAIDS, 2002.

6. Chacon-Cruz, E. Intestinal Protozoal Diseases. eMedicine J. 2003;3(5): sec. 1-11.
7. Joshi M, Chowdhary A.S, Dalal P.J. and Maniar J.K. Parasitic diarrhea in patients with AIDS. Natl Med J India 2002;15: 72-74.

8. Bern C, Glass R.I. Impact of Diarrhoeal Disease Worldwide. Infections of the Gastrointestinal Tract, 2nd ed., Marcel Derker, New York, 1994:1-26.

9. McGowan I, Chalmers A, Smith G.R, Jewell D. Advances in Mucosal Immunology. Gastroenterol Clin North Am 1997;26:145-173.

10. Cimerman S, Cimerman B, SalomoLewi D. Prevalence of Intestinal Parasitic Infections in Patients with Acquired Immunodeficiency Syndrome in Brazil. Int J Infect Dis 1999;3:203-206.

11. Giannella R.A. Gastroenterology Clinics of North America: Acute Infectious Diarrhoea. W.B. Saunders Company, Philadelphia. 1993;22(3):483622.

12. Fisseha B, Petros B, Woldemichael T, Mohammed H. Diarrhoea-associated Parasitic Infectious Agents in AIDS Patients within Selected Addis Ababa Hospitals. Ethiop. J. Health Dev. 1999;13(3): 169173.

13. Ortega Y, Adam R. Giardia: an overview and update. Clin. Infect. Dis.1997;25(3):545-549.

14. Lindo F.J, Levy A.V, Baum K.M, Palmer J.C. Epidemiology of Giardiasis and Cryptosporidiosis in Jamaica. AJTMH 1998;59(5):717-721.

15. Adegbola R.A, Demba E, Deveer G, Todd F. Cryptosporidium infection in Gambian children less than 5 years of age. J. Trop. Med. Hyg. 1994;97:103107.

16. Endeshaw T, Mohamod H.M, Tilahun, W. Cryptosporidium parvum and other intestinal parasites Among Diarrhoeal Patients Referred to EHNRI in Ethiopia. Ethiop. Med. J. 2004;42:195198.

17. Adamu H, Endeshaw T, Teka T, Kifle A, Petros B. The Prevalence of Intestinal Parasites In Paediatric Diarrhoeal and Non-Diarrhoeal Patients In Addis Ababa Hospitals, With Special Emphasis On Opportunistic Parasitic Infections and With Insight Into The Demographic and Socio-Economic Factors. Ethiop. J. Health Dev. 2006;20(1):39 - 46.

18. Lew F.A, Poles M.A, Dieterich D.T. Diarrhoea1 disease associated with HIV infection. Gastroenterol Clin North Am 1997;26:494-495.

19. Sorvillo F.J, Lieb L.E, Seidel J, Kerndt P, Turner J, Ash L.R. Epidemiology of Isosporiasis among persons with Acquired Immunodeficiency Syndrome in Los Angeles County. AJTMH 1995;53:656-659.

20. Awole M, Gebre Selassie S, Kassa T, Kibru G. Prevalence of Intestinal Parasites in South-Western Ethiopia. Ethiop. J. Health Dev. 2003;17(1):71-78.

21. Hailemariam G, Kassu A, Abebe G, Abate E, Damtie E, Mekonnen E, Ota, F. Intestinal Parasitic Infections in HIV/ AIDS and HIV Seronegative Individuals in a Teaching Hospital, Ethiopia. JPN J Infect Dis. 2004;57:41-43. 
22. Sarfati C, Bourgeois A, Menotti J, Liegeois F, Moyou-Somo R, Delaporte E, Derouin F, Mpoudi N, Molina, J.M. Prevalence of Intestinal Parasites Including Microsporidia in Human Immunodeficiency Virus-Infected Adults in Cameroon: A Cross-Sectional Study. AJTMH 2006;74(1):162-164.

23. Fleming A.F. Opportunistic infection in AIDS in developed and developing countries. Trans Royal Soc Trop Med Hyg 1990;84(1): 1-6.

24. Endeshaw T, Tadesse G, Petros, B. Significance of Blastocystis hominis in patients referred for bacteriological stool culture at EHNRI. Ethiop. J. Health Dev. 2006;21(1):61 - 67.

25. Bern C, Hernandez B, Lopez M.B, Arrowood M.J, De Merida M, Klein Robert, E. The Contrasting epidemiology of Cyclospora and Cryptosporidium among outpatients in Guatemala. AJTMH 2000;63(5, 6):231-235.
26. Ortega Y.R, sterling C.R, Gilman, R.H. Cyclospora cayetanensis. Adv. Parasitol. 1998;40: 399-418.

27. Carr A, Marriot D, Field A. Treatment of HIV-1associated Microsporidiosis and Cryptosporidiosis with Combination Antiretroviral Therapy. Lancet 1998;351: 256-61.

28. Foudraine N.A, Weverling G.J, Van Gool T. Improvement of Chronic Diarrhoea in Patients with Advanced HIV-1 Infection during Potent Antiretroviral Therapy. AIDS 1998;12:35-41.

29. Mekonnen G. (2007). Possible Interactions of Intestinal Helminth and HIV Infections: The situation in Fitche, Northern Oromiya. MSc Thesis. Addis Ababa University, Ethiopia.

30. Östan D, Kilimcioğlu A, Girginkardesler Nogay, Özyurt Beyhan, Limoncu E, Ok Ü. Health inequities: lower socio-economic conditions and higher incidences of intestinal parasites. BMC Public Health 2007;7:342. 